\title{
EL LUGAR DE JUAN A. MATEOS EN EL TEATRO MEXICANO
}

\author{
$\mathbf{P} \mathbf{O}$
}

\section{LUIS REYES DE LA MAZA}

CUANDO se habla de los autores teatrales mexicanos en el siglo xix, por lo general se trata siempre a los tres más famosos: Manuel. Eduardo de Gorostiza, Ignacio Rodríguez Galván y Fernando Calderón, que son, sin duda, los tres más importantes; pero no los únicos que lucharon por crear una literatura dramática nacional.

De 1850 a 1900 existieron más de cien dramaturgos mexicanos que escribieron algo más de trescientas obras entre dramas, comedias, óperas y zarzuelas. Allí está toda esa enorme producción en espera que alguien haga su estudio y la saque a luz, para demostrar que México cuenta con una tradición teatral iniciada en los albores del siglo pasado y continuada, cada vez con mayor entusiasmo, hasta nuestros días.

Entre estos autores sobresale don Juan A. Mateos, que ha sido posiblemente el más fecundo de nuestros dramaturgos. Su inmensa labor como novelista ha sido ya estudiada por varios investigadores; pero es rara la vez que se ha estudiado a Mateos como autor teatral, a pesar de que es en el teatro donde alcanza la fama en su tiempo.

Desgraciadamente casi la totalidad de los manuscritos de sus obras, muy pocas publicadas, se hallan perdidos, por lo que no se puede hacer un estudio concienzudo sobre su producción, y así, sólo podemos darnos cuenta de ella a través de las crónicas y programas aparecidos en los periódicos de la época.

La primera producción de Mateos fue hecha en colaboración con Vicente Riva Palacio, el gran novelista y militar mexicano. Los dos es- 
critores comienzan a trabajar teatralmente en esta fecha y no se separan hasta después de haber estrenado con indiscutible buen éxito más d. quince obras. Aquel primer estreno fue realizado en el Teatro de Iturbide el domingo 27 de enero de 1861 , poco después del triunfo de las fuerzas liberales, bajo el siguiente programa:

Grandiosa función de obsequio que al Excmo, señor Gobernador del Distrito don Justino Fernández, al Excmo. Ayuntamiento de esta capital y al gran partido liberal, le consagra con justa gratitud la compañía. Después de una brillante obertura se representará el drama en cuatro actos y en verso original de los señores don Vicente Riva Palacio y don Juan A. Mateos, titulado Odio Hereditario. Concluirá la función con el hermoso baile de la obertura de la Cenerentola ejecutado por la señora Sánchez y el señor Llenas. A las ocho en punto.

Lamentablemente no tenemos ni siquiera una idea de lo que trataba este primer drama de Mateos y Riva Palacio, pues aparte de que se encuentra perdido, los cronistas de la época no nos hablan de él como se debe, sino se limitan a reseñar el triunfo de los autores y a decirnos frases que nos dejan en la misma ignorancia:

A una versificación flúida y sonora, reúne escenas de interés que conmueven el ánimo de los espectadores. Los poetas fueron llamados tres veces a la escena; en la segunda recibieron unas coronas y en todas multitud de versos en su honor cayeron en el salón. Una música militar con que les obsequió el señor González Ortega les saludó con dianas cuando se presentaron en el foro yl en seguida los fue a acompañar hasta la casa del señor Riva Palacio.

Esto es lo más que dice Manuel M. de Zamacona, crítico eventual de espectáculos.

Pronto se anuncia una nueva obra de los jóvenes autores. El domingo 19 de marzo de 1861 se estrena en el Teatro de Iturbide, en función dedicada "al señor general don Ignacio Zaragoza y a los jefes, oficiales y tropa que componen la brillante división de Zacatecas, y a la que honrará con su asistencia el Excmo. señor Presidente sustituto de la República don Benito Juárez", la comedia en tres actos titulada Borrascas de un Sobretodo, original de Juan A. Mateos y Vicente Riva Palacio. La comedia, cuyo título parodia el del famoso drama del autor español Tomás Rodríguez Rubí y que estaba causando por esos días verdadero furor en el Gran Teatro Nacional: Borrascas de un Corazón, alcanzó un buen éxito considerable, y con esto los dos autores afianzan su reputación de "los primeros dramaturgos nacionales". 
Bien puede decirse que Mateos y Riva Palacio fueron los iniciadores de lo que ahora llamamos "sketch" político, pues su juguete cómico en un acto y en verso, estrenado el 15 de agosto de ese mismo año de 1861, titulado El Incendio del Portal de Mercaderes, no es sino un acopio de citas humorísticas de actualidad en las que se satiriza a los personajes políticos. Inmediatamente después, el 7 de septiembre, otro nuevo juguete cómico político es llevado a la escena del Iturbide con el título de La ley del Uno por Ciento, que alcanzó tanto o más éxito que el anterior. Francisco Zarco, director' del periódico más importante de la época, "El Siglo XIX", no puede callar más tiempo la indignación que siente ante estas innovaciones teatrales y lanza un gran artículo del que entresacamos los siguientes párrafos:

"En El Incendio del Portal y en La Ley del Uno por Ciento faltan la sal ática, el verdadero y fino epigrama, el chiste cómico, y en vez de estas dotes, sólo hay nombres de actualidad y frases que dan a la pieza color local, tristes recursos que no inmortalizarán obras que para ponerse en escena de aquí a diez años necesitarán más notas que las que Clemencín puso al Quijote... El sainete tiene muy poco que ver con la ley del uno por ciento, y lo mismo pudo llamarse, como se llama, El disecador de pájaros, El perico disecado o La inundación de la calle del Refugio, pues la gran novedad es una decoración, en verdad muy bien pintada por el señor Serrano, que representa la parte de la calle del Refugio en que está el hotel en un rato de inundación. Los autores necesitan de este aparato escénico y de episodios de brocha gorda como el comediante vestido con ropa igual a la del jefe de policía y los cargadores que llevan en hombros a los transeúntes en una calle anegada."

A pesar de lo que haya dicho el crítico Zarco, nosotros opinamos, si bien a cien años de distancia, que esos sainetes tuvieron una importancia realmente primordial dentro de la historia de nuestro teatro, puesto que, repetimos, fueron los primeros intentos de un género que medio siglo después alcanzaría un auge de primera magnitud: la revista satíricopolítica.

El 16 de septiembre de 1861 se estrena, también en el Teatro de Iturbide, la obra ganadora del concurso convocado por el Estado para premiar una producción teatral con tema patriótico, y esta obra lo fue El abrazo de Acatempan o el primer dia de la bandera nacional, cuyos autores no podian ser otros que Mateos y Riva Palacio. Es este un drama dividido en tres actos $y$ en verso en el que la demagogia y el patrioterismo campean sin discreción; pero sus creadores no buscaban 
sino llevarse el premio, lo que consiguieron, y no les importó el cuidado del estilo ni de la técnica. Para dar una idea al lector de lo que es este drama, transcribimos a continuación la escena final. Fernando, el protagonista, aparece con la bandera tricolor ondeándola con fuerza, truco que se usará continuamente desde entonces en todos los teatros cuando no se está seguro de arrancar el aplauso por la obra misma, y así, al menos, el espectador aplaude a su bandera. Fernando, seguido de soldados insurgentes y de pueblo, adelantándose al proscenio, sin cesar de agitar la enseña patria, dice:

FERNANDO.-Miradla, hermanos, se levanta cual sol entre la bruma para llegar triunfante en vuestras manos

al palacio imperial de Moctezuma. Miradla aquí, salud en este día al lábaro triunfal del insurgente su ardiente luz de libertad envía, $y$ se levanta un pueblo independiente $\mathrm{y}$ a sus alas agita la victoria, sacude el pueblo su letargo inerte... $\mathrm{Y}$ ansioso ya de libertad y gloria lanza un grito: i Independencia o muerte! Se agrupa en derredor de su bandera, viste la libertad su pompa y galas;, y de Anáhuac el águila altanera al bélico clamor tiende sus alas. Pueblos del Septentrión, jalzad la frente!, tremola ya vuestro sagrado emblema, no más esclavitud, que eternamente sobre ese nombre caiga el anatema... Signo de nuestra fe, bandera santa (SE ARRODILLAN) que a un pueblo cubres con benigna sombra cuando por ti ese pueblo se levanta, con qué ternura en su pasión te nombra. Naciste en un rincón de la montaña, hija del pueblo que en su fe te cría, plantada en la región de Nueva España; el porvenir te merecerá algún dia, el bautismo será de tu carrera la sangre de valientes campeones y orgullosa serás nuestra bandera aunque flotes al aire hecha jirones. Tú vas a ser del pueblo la existencia, del pasado tu sombra nos divide.

GUERRERO.-i Viva México libre! ; Independencia! 
DOI: http://dx.doi.org/10.22201/iie.18703062e.1957.26.635

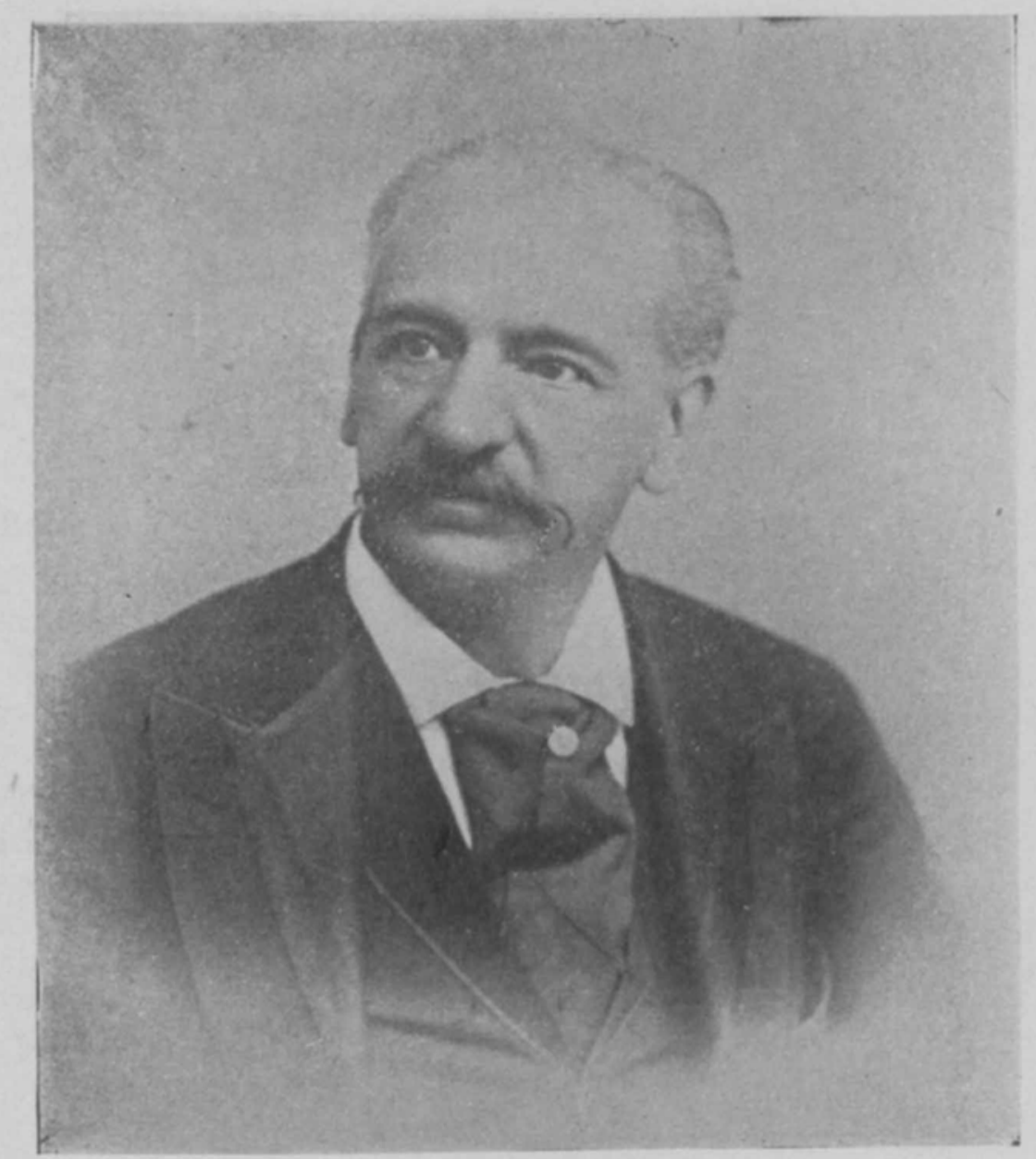

Juan A. Mateos. 
DOI: http://dx.doi.org/10.22201/iie.18703062e.1957.26.635

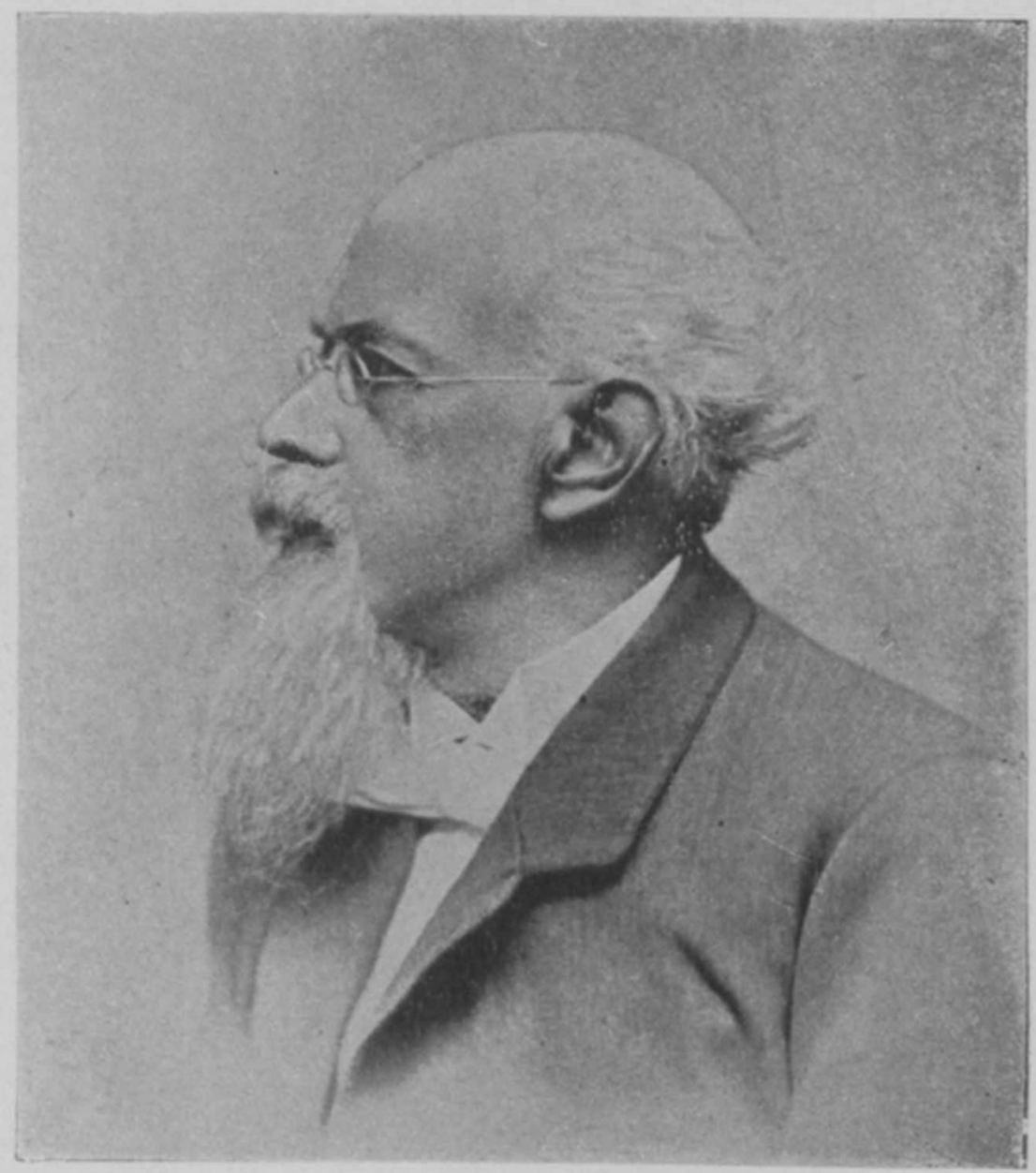

Vicente Riva Palacio. 
Mateos y Riva Palacio, juntos pertenecen también a los fundadores de un auténtico teatro mexicano. Tratan en sus obras problemas y personajes del pueblo, logrando con esto desconcertar al público y a la crítica, que sólo aceptaba las obras del repertorio español. En la comedia La hija del cantero, estrenada en el Gran Teatro Nacional en 1862, hacen la primera tentativa por llevar a la escena el costumbrismo a lo largo de tres actos en verso. Entre las muchas críticas que recibieron, adversas la mayor parte, se encuentra la del novelista y también autor dramático queretano Hilarión Frías $\mathrm{y}$ Soto, que exclama lleno de entusiasmo en el periódico jocoso político La Orquesta:

"... es una de las mejores producciones de los conocidos poetas mexicanos; la fluidez de la versificación, lo interesante del argumento y el desarrollo bien combinado de las escenas forman el todo de esta bellísima composición. Hasta hoy se veía con desagrado, o por lo menos con frialdad, el que se trajese a la escena algo mexicano. Acostumbrado el público a la representación de las piezas extranjeras, era necesario afrontar con las primeras impresiones que necesariamente debían causar asuntos del país puestos en escena."

Los dos autores encuentran en la comedia mayor facilidad de expresión, y a ella se dedican por entero. Al mediar el año de 1862, estrenan la comedia titulada La política casera, y no tenemos más referencia de ella que lo que dice el anónimo cronista del semanario burlesco La Madre Celestina:

"Es un argumento sencillo que marcha sin fatiga ni inverosimilitud a su desenlace; han sabido (los autores) sembrar multitud de escenas llenas de chiste y verdadera sal cómica, gracias a la verdad y maestría con que están acabados los personajes que en ella figuran. Los señores Mateos y Riva Palacio nos acaban de dar una prueba de su talento $y$ de su conocimiento de la sociedad en la producción que nos ocupa."

Algunos meses después estrenan una nueva comedia, Temporal $y$ Eterno, esta vez exclusivamente de costumbres, y alcanzan, en todas las críticas, los mayores elogios. Hasta Francisco Zarco, que como hemos visto los había atacado sistemáticamente, dice de ella:

"... abunda en chistes de buena ley, está bien tramada, hace reír, y tiene el alto fin moral de corregit y ridiculizar la hipocresía. Se dirá que el asunto no es nuevo y que después del Tartufo quedó 
completamente agotado; pero esto no obsta para que Temporal $y$ Eterno sea original y ofrezca un bonito cuadro de costumbres mexicanas copiado d'après nature."

En ese mismo 1862 vuelven los autores a tratar los temas políticos de actualidad, confiados en el éxito que obtuvieron anteriormente con el mismo género, y estrenan la comedia en un acto titulada El tirano doméstico, que no es más que una sátira en contra de Juan Nepomuceno Almonte, el traidor que animó a Napoleón III a enviar sus tropas invasoras contra México. Como era de esperarse, el buen éxito obtenido por esta comedia fue tan grande como si se tratara de una producción de Manuel Bretón de los Herreros, el autor cómico español de más boga entonces. He aquí un trozo, el más aplaudido según los diarios, de El tirano doméstico:

Estás para bien saber que éste era un conservador, tan indio como el mejor y que noble vino a ser. El siempre, de orgullo lleno, se olvidó allá en Inglaterra que era el topil en su tierra llamado Juan Pamuceno. Yendo días, el señor dijo a tres reinos: i Ya escampa! $\mathrm{Y}$ cual si fuera chinampa vendió a su patria, Iqué horror!

Quería el indio ladino al mirarse en su abandono hallar en México un trono cual si fuera Constantino. En su perfidia y traición el hombre, con mucho taco, con un ministro de Baco ${ }^{1}$ gritaron: ¡Intervención!

"Allá con unos muñecos, con una bomba de a placa toda la indiada se aplaca como en Argel y Marruecos." $\mathrm{Al}$ renegado ya viejo se acercó una encantadora y le dijo: "Mira ahora",

1 Saligny, ministro de Francia en México. 


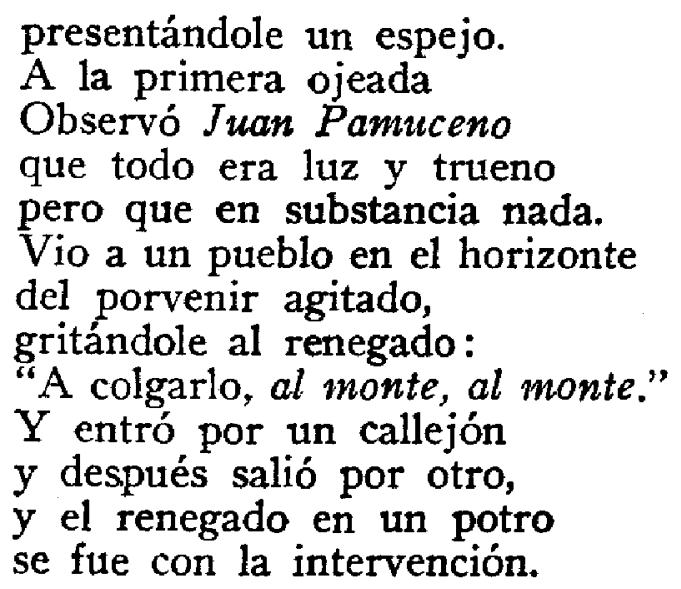

Dos meses más tarde, al tenerse noticia de la victoria alcanzada en Puebla el 5 de mayo, Mateos y Riva Palacio cambiaron este trozo por el que sigue, para darle mayor actualidad a la comedia, y volvieron a llevarla a la escena del Iturbide alcanzando catorce representaciones consecutivas, caso insólito en los teatros de la capital:

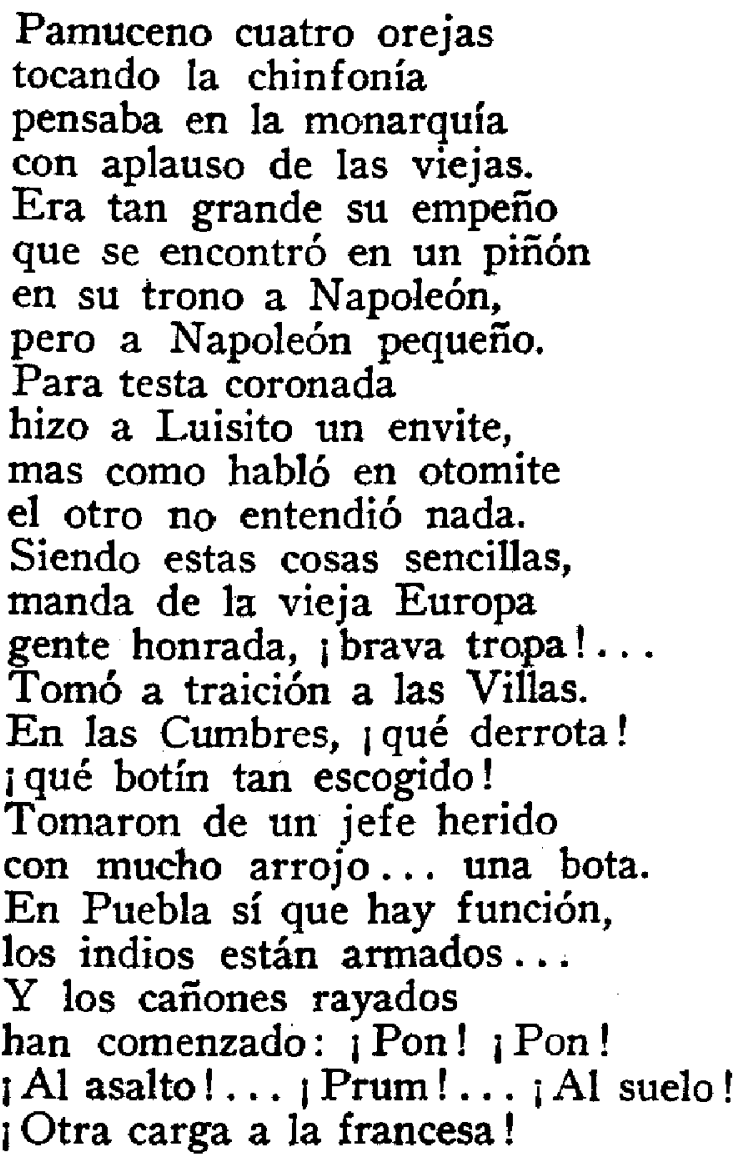




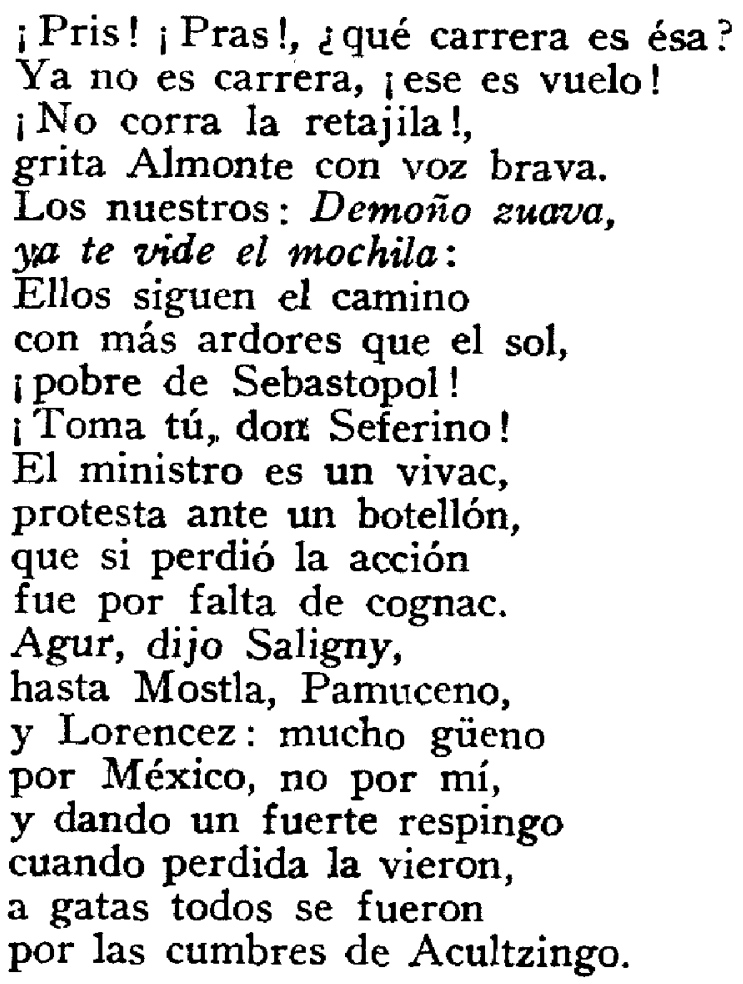

El público gustó de la comedia, pero los críticos se indignaron ante esta nueva manera de hacer reír. Zarco volvió a sus ataques contra Mateos y Riva Palacio:

"Si bien la prensa periódica tiene a veces que descender al triste terreno de las apreciaciones personales, el teatro debe limitarse a tratar de defectos y vicios generales para corregirlos, y no conviene a su dignidad los ataques individuales, ni los nombres propios de los contemporáneos."

Alentados por estos triunfos, los autores escriben, durante este año de 1862, tres comedias más: La catarata del Niágara, contra la invasión norteamericana de 1847; La politicomania y Nadar, y a la orilla ahogar, esta última diferente a las demás, puesto que se trata de una comedia de época, cuya acción transcurre en el siglo xvI, y que fue un rotundo fracaso. Siempre siguiendo al crítico Zarco, leemos:

"es de desearse que los señores Riva Palacio y Mateos prescindan de imitaciones sin objeto y se decidan a emprender obras originales, que tengan algún plan moral. Es de desear también que cada uno trabaje solo, pues está visto ya que entre dos no pueden hacerse grandes obras literarias". 
Viene luego el triunfo de la invasión francesa y el establecimiento del segundo imperio, y Riva Palacio, siempre fiel y valiente partidario de Juárez, se retira junto con él y su ministerio de la capital. Mateos permanece en ella y sigue escribiendo él solo algunos dramas y comedias. Es uno de los pocos autores mexicanos que estrena sus producciones durante esos años. En 1864 da a la escena La muela del juicio, y en 1865 Luna de miel, de la que el poeta Luis G. Ortiz dice desde las páginas de "El Siglo XIX" en 1867, año en que volvió a ponerse la comedia:

"Esta bonita composición ha sido recibida con agrado siempre que se ha ejecutado. Es una pintura triste, pero desgraciadamente exacta, es igualmente cierto que, en lo general, ese fuego devorador se convierte en llama apacible y constante que alumbra y da calor delicioso al hogar doméstico; a menos que el viento tempestuoso de la discordia o alguna otra desgracia liegue a apagarla para siempre."

También en 1865, Mateos estrena dos comedias más: Convulsión de idioma, sátira contra los mexicanos que a toda costa trataban de aprender el francés, y La calle de enmedio, que fracasa la noche misma del estreno entre el descontento general. Al día siguiente Mateos retira su comedia del teatro y envía a los diarios capitalinos la siguiente carta :

"Señores redactores. Muy señores míos: La noche del domingo se ha puesto en escena en el Teatro Principal mi última composición dramática intitulada $L a$ calle de enmedio. Mi producción ha sido recibida con frialdad por el público, y acaso su galanteria me ha librado de un mal momento. Seis composiciones dramáticas he dado en la temporada cómica, todas ellas han merecido el favor público y con éxito, que hoy' me sirve de orgullo, puesto que la reprobación de La calle de enmedio me hace ver que aquellas ovaciones fueron sinceras. El único juez que reconozco en las obras literarias es el público, y no pretendiendo ser más que Scribe, Voltaire y Víctor Hugo, que han sufrido silbas en sus comedias, me descubro la frente ante este fallo justiciero y retiro de la escena mi comedia. Nutrido el público con esas obras modernas de Larra, Eguilaz, Ayala y otros genios prominentes de la literatura española, mis composiciones aparecerán siempre débiles en el foro; pero siendo el único que en la actualidad cultiva ese género en todo el país, procuraré por medio del estudio y la dedicación hacerme digno de esos aplausos prodigados en todas mis composiciones y hoy negados con justicia a La calle de enmedio... Juan A. Mateos."

A la caída de Maximiliano y el restablecimiento de la República, Riva Palacio no vuelve a asociarse con Mateos, y se dedica por entero 
a la novela. En cambio Mateos sigue con su producción dramática siempre fecunda. La muerte de Lincolm (1868), El plagio (1872), El novio oficial (1872), El otro (1878), Los dioses se van (1878), La monja Alférez (1880), etcétera, hasta alcanzar más de treinta títulos sin contar las quince escritas en colaboración con Riva Palacio. Llega hasta hacer libretos para zarzuelas en las postrimerias del siglo, como Revista de guante blanco, en 1891, con música de José Austri, y El sueño de un loco, en 1904, con música del maestro Jordá.

En 1902 estrena su adaptación teatral de la famosa novela de Víctor Hugo Los miserables, en el Teatro Orrin, y obtiene un buen éxito de público y de crítica.

Su última obra, escrita a los setenta y nueve años de edad, 1910, y estrenada en el Teatro Hidalgo en medio de los aplausos de un público cariñoso que supo recompensar la fecunda e incansable labor del más entusiasta de los dramaturgos mexicanos, fue Juana de Arco. Al tocar ese tema que todo autor dramático de valía ha desarrollado con más o menos fortuna, vio el anciano Mateos las mejores críticas de toda su carrera :

"El conocido literato don Juan A. Mateos nos ha regalado con una bella pieza dramática en tres actos $y$ en verso, que viene a poner de manifiesto una vez más el mérito literario del viejo escritor mexicano y a demostrar que en algo útil emplea los últimos años de su laboriosa vida. La obra en cuestión es un drama histórico que nos da a conocer la personalidad de la valerosa heroína francesa. Está escrita con maestría y tiene pasajes y detalles trazados con vivo y hermoso colorido. El señor Mateos se hizo acreedor a una entusiasta $y$ calurosa ovación que le tributó la concurrencia entusiasmada ante los cuadros que le acababa de presentar el autor." (Crónica sin firma aparecida en Revista de Revistas.)

En 1913 concluye la vida de este autor dramático nacional que abarcó extensamente los campos literarios de la poesía, la novela y el teatro y que, por ello, debe ocupar un prominente lugar dentro de la historia de nuestras letras, sin olvidar que ha sido uno de los principales y más importantes innovadores del teatro mexicano. 